\title{
Violência nas Relações Íntimas entre Parceiros do Mesmo Sexo: Estudo de Prevalência
}

\author{
Ana Maria R. Santos \\ Sónia Maria Martins Caridade ${ }^{1}$ \\ Faculdade de Ciências Humanas e Sociais, Universidade Fernando Pessoa, Porto, Portugal
}

\section{Resumo}

Este estudo procurou caracterizar a prevalência da violência nas relações íntimas entre parceiros do mesmo sexo em Portugal, recorrendo às Escalas de Táticas de Conflito Revisadas. Participaram neste estudo 168 participantes, com idades compreendidas entre os 18 e os 35 anos, cuja média de idade foi de 22,5 anos $(D P=3,79)$, sendo a maioria do sexo feminino $(76,2 \%)$. Em termos de perpetração, os resultados revelaram uma elevação da agressão psicológica (70,2\% na ligeira e 29,8\% na severa); uma ligeira elevação dos atos que não deixam sequelas ( $26,8 \%$ no ligeiro e $9,5 \%$ no severo) e, ainda, uma preponderância da coerção sexual ligeira (28\%). Em relação a vitimação, constatou-se igualmente uma preponderância da agressão psicológica ligeira $(69,2 \%)$. Os homens admitiram adotar mais comportamentos de coerção sexual, tanto na forma ligeira como severa. Foi ainda possível apurar a existência de uma relação positiva e significativa entre a duração do relacionamento íntimo e a vitimação por agressão psicológica ligeira. Estes resultados apelam à elaboração de respostas de apoio específicas para os diferentes tipos de vítimas, bem como a aposta na implementação de esforços preventivos mais contextualizados às diferentes realidades.

Palavras-chave: Violência, relações íntimas, parceiros do mesmo sexo, prevalência.

\section{Violence in Intimate Relationship between Same Sex Partners: Prevalence Study}

\begin{abstract}
This study aimed to characterize the prevalence of violence in intimate relationships between same-sex partners in Portugal using the Revised Conflict Tactics Scales. The study included 168 participants, mainly women (76.2\%), who were between 18 and 35 years of age with an average age of $22.5(S D=$ 3.79). In terms of perpetration, the results showed higher rates for psychological aggression $(70.2 \%$ mild and $29.8 \%$ severe), physical abuse that leaves no sequelae (26.8\% mild and $9.5 \%$ severe) and mild sexual coercion (28\%). Regarding victimization, a high rate of minor psychological aggression $(69.2 \%)$ was also found. The men admitted to adopting more behaviours related to both minor and severe sexual coercion. A positive and significant relationship was found between the duration of an intimate relationship and victimization by minor psychological aggression. These results suggest the need to develop specific support interventions for different types of victims, as well as the need to implement more prevention efforts tailored to different situations.
\end{abstract}

Keywords: Violence, intimate relationships, same-sex partners, prevalence.

Endereço para correspondência: Universidade Fernando Pessoa, Faculdade de Ciências Humanas e Sociais, Praça 9 de Abril, 349, Porto, Portugal 4249-004. Fone: +351225071300 Fax: +351225508269. E-mail: soniac@ ufp.edu.pt 


\section{La Violência en las Relaciones Íntimas de Personas del Mismo Sexo: Estudio de Prevalencia}

\section{Resumen}

Este estudio trata de caracterizar la prevalencia de la violencia en las relaciones íntimas entre parejas del mismo sexo en Portugal, utilizando la Escala Táctica de Conflictos Revisada. El estudio incluyó 168 participantes, de edades comprendidas entre los 18 y 35 años, cuya edad media fue de $22.5(D E=3.79)$, la mayoría de los cuales eran mujeres (76.2\%). En cuanto a la agresión, los resultados mostraron un aumento en la agresión psicológica (70.2\% en agresiones leves y graves en el $29.8 \%$ ); un ligero aumento de los actos que no dejan secuelas (26.8\% leves y $9.5 \%$ graves) y también un ligero predominio de la coacción sexual (28\%). En el nivel de victimización, también se encontró una ligera preponderancia de la agresión psicológica (69.2\%). Los hombres admitieron que realizan más conductas de coacción sexual, tanto en forma leve y grave. También fue posible determinar la existencia de una relación positiva y significativa entre la duración de la relación íntima y la victimización por agresiones psicológica leves. Estos resultados apelan a la elaboración de respuestas específicas de apoyo a los diferentes tipos de víctimas, así como a una apuesta en el desarrollo e implementación de medidas preventivas más adecuadas a las diferentes realidades.

Palabras clave: Violencia, relaciones intimas, parejas homosexuales, prevalencia

A violência nas relações íntimas assume-se como um sério problema, sendo atualmente considerado uma questão de saúde pública. Efetivamente, a literatura comprova que esta forma de violência nas relações íntimas poderá apresentar custos elevados para a saúde das vítimas, conduzindo, por exemplo, a uma maior propensão para o desenvolvimento da dor crônica, ao desenvolvimento de diversos problemas psicológicos, como a depressão e a ansiedade (Carvalho, Lewis, Derlega, Winstead, \& Viggiano, 2011; Little \& Terrance, 2010).

A investigação acerca deste fenômeno teve início na década de 70 como consequência do reconhecimento social da violência nos relacionamentos íntimos, nomeadamente da violência contra as mulheres na família (Jasinski \& Williams, 1998). Tradicionalmente, a investigação nesta área incide essencialmente em relações de natureza heterossexual, na qual a mulher é tendencialmente identificada como a principal vítima e o homem o agressor (Richards, Noret, \& Rivers, 2003). Tal experiência refletiu-se em uma menor exploração e investigação de outros tipos de relacionamentos como acontece nas situações de violência nas relações de intimidade entre parceiros do mesmo sexo (Cezario, Fonse- ca, Lopes, \& Lourenço, 2015; Finneran \& Stephenson, 2012; Santos, 2012). Sem duvidar da existência de uma representação da violência em relacionamentos envolvendo parceiros heterossexuais, vários estudos (e.g., Banks \& Fedewa, 2012; Finneran \& Stephenson, 2012; National Coalition of Anti-Violence Programs Project, 2013) têm discutido que esta é uma problemática também presente em relacionamentos homossexuais, contrariando, desta forma, a caracterização generalizada destas relações como sendo igualitárias e, consequentemente isentas de violência íntima (Antunes \& Machado, 2005). Assim, os estudos neste âmbito têm revelado características comuns nas formas de violência presentes tanto em relações homossexuais como heterossexuais, integrando comportamentos abusivos físicos, psicológicos e sexuais (Antunes \& Machado, 2005; Cezario et al., 2015; Finneran \& Stephenson, 2012).

Um estudo desenvolvido numa comunidade de jovens GLB (gays, lésbicas e bissexuais) dos EUA, por Freedner, Freed, Yang e Austin (2002), no qual contaram com 521 participantes, averiguaram que $41,5 \%$ dos gays e $37,1 \%$ das lésbicas relataram pelo menos um incidente de violência nos seus relacionamentos. No 
seguimento desta investigação foi possível verificar-se um estudo realizado, no mesmo país, com 117 adolescentes homossexuais, cujos resultados referiram que $1 / 4$ dos/as participantes já tinha experienciado algum tipo de violência por parte do/a seu/sua parceiro/a e, um em cada dez, relatou a existência de vitimação física, demonstrando, assim, que a violência íntima é um problema significativo para os/as adolescentes envolvidos/as em relações de intimidade com pessoas do mesmo sexo (Halpern, Young, Waller, Martin, \& Kupper, 2004).

Em outra investigação realizada por Carvalho e seus colaboradores (2011), com uma amostra norte-americana de 581 homossexuais de ambos os sexos, verificou-se que $24,2 \%$ dos/ as participantes era vítima de violência nas suas relações íntimas e $8,3 \%$ dos/as participantes do referido estudo relatou a adoção de comportamentos violentos nas suas relações de intimidade.

Mais recentemente, um outro estudo desenvolvido na China por Yu, Xiao e Liu (2013), no qual participaram 418 homens homossexuais e 330 homens heterossexuais, procurou comparar a incidência de violência nas relações de intimidade entre estes dois grupos em cinco áreas: sentimento de controle, abuso emocional, medo pela sua segurança, violência física e violência sexual. Assim, 32,8\% dos homens homossexuais e $8.8 \%$ dos heterossexuais revelaram que tinham experienciado, pelo menos, um dos cinco tipos de abuso. Além disso, 82 gays $(9,6 \%)$ relataram que os seus parceiros tentaram controlar as suas atividades diárias, nomeadamente locais onde iam e com quem falavam, 11,2\% dos participantes homossexuais referiu que haviam sido insultados e humilhados na presença de outras pessoas, $12,7 \%$ informou que temia pela sua segurança face a ameaças dirigidas pelos seus companheiros e $7,9 \%$ admitiu que havia sofrido violência física. Dos indivíduos que relataram a existência de experiências abusivas, $83,9 \%$ dos homens homossexuais e $20,7 \%$ dos homens heterossexuais afirmaram que nunca revelaram as mesmas a ninguém.

Um outro estudo recente foi conduzido por Edwards e Sylaska (2013) com estudantes uni- versitários norte-americanos que mantinham relações amorosas com parceiros do mesmo sexo. Assim, numa amostra de 391 homossexuais, a violência física surgiu como sendo a mais relatada $(19,9 \%)$, seguida do abuso psicológico $(12,5 \%)$ e sexual $(10,5 \%)$ por parte do parceiro. Ainda nesta amostra, verificou-se que, cerca de $1 / 3$ da mesma, relatou a prática de qualquer forma de violência nas suas relações e $22,3 \%$ afirmou que a violência era bilateral.

A revisão da investigação internacional nesta área permite-nos perceber que é no continente americano que se verifica um maior investimento no estudo da violência nas relações íntimas entre pessoas do mesmo sexo (cf. Cezario et al., 2015). Assim, conhecida a extensão do fenômeno e implicações do mesmo também no nível das relações íntimas entre parceiros/as do mesmo sexo, importa ampliar a investigação a outros países, incluindo Portugal, atendendo ao ínfimo investimento registrado neste âmbito.

Não obstante, foi possível encontrar dois estudos desenvolvidos com vistas a caracterizar a prevalência da violência nas relações de intimidade na comunidade homossexual (Antunes \& Machado, 2005; Costa, Machado, \& Antunes, 2011). No estudo sobre violência entre parceiros/as do mesmo sexo, desenvolvido por Antunes e Machado (2005), verificou-se que, de 63 participantes homossexuais de ambos os sexos, 20,6\% dos indivíduos admitiu ter sido vítima de violência na relação atual e 15,9\% reconheceu a adoção de comportamentos violentos com os/as seus/suas companheiros/as. No que diz respeito às relações anteriores, $61,9 \%$ da amostra referiu comportamentos abusivos adotados pelo/a parceiro/a, enquanto $46 \%$ admitiu o recurso a violência contra o/a companheiro/a (Antunes $\&$ Machado, 2005). No mesmo sentido, Costa e seus colaboradores (2011), através de uma amostra de 151 participantes homossexuais, de ambos os sexos e com idades compreendidas entre os 15 e os 60 anos, e com referência ao ano anterior ao estudo, verificaram que $35,1 \%$ dos/as inquiridos/as relatou ter sido vítima de violência emocional, $24,5 \%$ admitiu ter sido alvo de violência física pelo/a parceiro/a e 3,3\% revelou ter sofrido de violência sexual pelo/a companheiro/a. No 
que concerne à adoção de comportamentos abusivos, 30,5\% da amostra revelou ter perpetrado pelo menos um ato de violência emocional sobre o/a seu/sua companheiro/a, sendo que $24,5 \%$ relatou ter sido fisicamente violento/a em relação ao/à seu/sua companheiro/a e $0,7 \%$ admitiu ter cometido pelo menos um ato de violência sexual contra o/a parceiro/a.

Embora haja menor investimento científico no estudo da violência nas relações íntimas na população homossexual, as evidências comprovam que este é um problema que não pode mais ser ignorado. A existência de um número indeterminado de pessoas homossexuais em todo o mundo, na medida em que, a homossexualidade e respectivos relacionamentos ainda são mantidos num sistema fechado (Antunes \& Machado, 2005), impedem conhecer com exatidão a proporção deste fenômeno (Little \& Terrance, 2010; Yu et al., 2013), que poderá ter um alcance maior e afetar muito mais indivíduos do que estes estudos têm vindo a demonstrar.

O presente estudo quantitativo, ao incidir sobre a problemática da violência nas relações de intimidade entre sujeitos do mesmo sexo, nas suas diversas formas (psicológica, física e sexual) pretende contribuir para um aprofundamento do estudo da violência ocorrida neste tipo de relacionamentos, no contexto português. Neste sentido, com a realização deste estudo, pretendeu-se recolher dados sobre a prevalência dos diferentes comportamentos abusivos ocorridos nos relacionamentos entre indivíduos do mesmo sexo, durante o último ano. De forma mais específica, pretendeu-se: determinar a prevalência da vitimação e perpetração das diferentes formas de violência íntima; identificar os fatores sociodemográficos (e.g., sexo) relacionais e formativos (e.g., tipo de relacionamento íntimo; duração do relacionamento íntimo) associados aos diferentes tipos de abuso (em termos de vitimação e agressão).

\section{Método}

\section{Participantes}

A amostra foi constituída por 168 participantes, dos quais $128(76,2 \%)$ pertencem ao sexo feminino e $40(23,8 \%)$ ao sexo masculino (Tabela 1). A idade dos/as participantes encontra-se compreendida entre os 18 e os 35 anos $(M=22,50 ; D P=3,79)$.

Em relação às habilitações literárias, foi possível constatar-se que $48,2 \%$ dos/as participantes situaram a sua escolaridade ao nível $\operatorname{dos} 10^{\circ}-12^{\circ}$ ano e $7,1 \%$ ao nível dos $7^{\circ}-9^{\circ}$ ano, $30,4 \%$ dos indivíduos referiu possuir uma licenciatura, $13,7 \%$ o $2 .^{\circ}$ ciclo de estudos (mestrado) e apenas $0,6 \%$ dos/as participantes se apresentou como sendo doutorado/a. Relativamente à situação profissional, mais de metade dos/as participantes (56\%) indicou ser estudante, 26,2\% referiu encontrar-se no ativo e 17,9\% em situação de desemprego.

Uma reduzida parte da amostra $(0,6 \%)$, embora tivesse referido a existência de relacionamentos íntimos homossexuais no último ano, atualmente encontrava-se em relações heterossexuais. Mais de metade da amostra $(60,1 \%)$ encontra-se atualmente numa relação, a maioria solteira $(92,9 \%), 6.5 \%$ casada/união de facto e $0,6 \%$ divorciada/separada (cf. Tabela 2 ). No que se refere à última relação íntima entre parceiros/ as do mesmo sexo, tendo esta ocorrido no último ano, verificou-se que $89,9 \%$ tinha uma componente sexual e 71,4\% era sem coabitação. Considerando a duração do último relacionamento íntimo com sujeitos do mesmo sexo, $31 \%$ indicou uma duração igual ou superior a 2 anos, 12,9\% uma duração entre 1 a 2 anos, para $7,7 \%$ a duração da relação foi de aproximadamente 1 ano, para $10,7 \%$ entre os 6 e 11 meses, para $14,3 \%$ entre 3 a 5 meses, 4,2\% aproximadamente 2 meses e $1,8 \%$ da amostra reportou durações de aproximadamente 1 mês e menos de 1 mês.

\section{Instrumentos}

Os instrumentos utilizados neste estudo foram as Escalas de Táticas de Conflito Revisadas (CTS-2 - Strauss, 1979, traduzido e validado por Paiva \& Figueiredo, 2006) e um questionário sóciodemográfico elaborado para o efeito. O CTS-2 é um instrumento traduzido e validado para a população portuguesa que permite avaliar as diferentes táticas de resolução de conflitos adotadas (e.g. negociação) e, mais particularmente, determinar a prevalência das 
Tabela 1

Caracterização Sociodemográfica dos Participantes

\begin{tabular}{llcc}
\hline & & $\begin{array}{c}\text { Frequência Relativa } \\
(\%)\end{array}$ & $\begin{array}{c}\text { Frequência Absoluta } \\
(n)\end{array}$ \\
\hline Sexo & Masculino & 23,8 & 40 \\
& Feminino & 76,2 & 128 \\
Habilitações Literárias & Do $7^{\circ}$ ao $9^{\circ}$ Ano & 7,1 & 12 \\
& Do $10^{\circ}$ ao $12^{\circ}$ Ano & 48,2 & 81 \\
& Licenciatura & 30,4 & 51 \\
& Mestrado & 13,7 & 23 \\
& Doutoramento & 0,6 & 1 \\
& Desempregado/a & 17,9 & 30 \\
& Estudante & 56 & 94 \\
& No ativo & 26,2 & 44 \\
Estado Civil Profissional & Solteiro/a & 92,9 & 156 \\
& Casado(a)/ União de facto & 6,5 & 11 \\
& Divorciado/a /Separado/a & 0,6 & 1 \\
\hline
\end{tabular}

Tabela 2

Caracterização do Último Relacionamento Íntimo com Parceiros do Mesmo Sexo

Frequência relativa Frequência absoluta $(\%)$ $(n)$

Estado relacional atual

Duração da última relação homossexual

Tipo de relacionamento íntimo homossexual

O relacionamento íntimo tem/ tinha uma componente sexual
Atualmente, estou numa relação amorosa

60,1

Atualmente, não tenho qualquer relação amorosa, mas já tive no passado

Menos de 1 mês

$$
1,8
$$

Aproximadamente 1 mês

Aproximadamente 2 meses

$$
4,2
$$

3-5 meses

14,3

6-11 meses

10,7

Aproximadamente 1 ano

Mais de 1 e menos de 2 anos

17,9

2 anos ou mais

31,0

52

Com coabitação

28,0

47

Sem coabitação

71,4

Sim

89,9

151

Não 
diferentes formas de abuso (físico sem sequelas, físico com sequelas, psicológico e coerção sexual) e os seus níveis de severidade, no contexto familiar (ligeiro ou severo). Esta é uma escala de autopreenchimento, constituída por 39 itens que se encontram agrupados em pares de perguntas, destinados tanto ao/à inquirido/a como ao/à seu/sua companheiro/a. Neste sentido, o questionário supracitado encontra-se organizado num total de 79 questões e cujo tempo médio de administração se encontra nos 15 minutos, dividido em 5 subescalas. Assim, a negociação é avaliada em 12 itens (e.g., "Sugeri um acordo para resolver um desentendimento"), a agressão psicológica em 16 itens (e.g. ,"Gritei ou berrei à minha companheira"), o abuso físico sem sequelas em 24 itens (e.g., ligeiro: "Dei uma bofetada à minha companheira", severo: "Queimei ou escaldei a minha companheira de propósito"), a coerção sexual em 14 itens (e.g., ligeiro: "Insisti em ter relações sexuais quando a minha companheira não queria mas não usei força física", severo: "Usei a força (ex: ferindo, detendo, ou usando uma arma) para fazer com que a minha companheira tivesse relações sexuais comigo"), o abuso físico com sequelas em 12 itens (e.g., ligeiro: "Senti uma dor física, que se manteve no dia seguinte, por causa de uma luta com a minha companheira", severo: "Desmaiei porque a minha companheira me atingiu na cabeça durante uma luta").

A escolha sobre o instrumento recaiu pelo facto de permitir obter dados acerca dos dois elementos do casal e determinar as táticas de resolução de conflitos adotadas por cada um, mesmo que o questionário seja respondido apenas por um dos elementos do casal, durante o último ano, contabilizando o número de ocorrências através de oito categorias de resposta: as primeiras seis com vista à determinação da prevalência e cronicidade [(1) uma vez no ano anterior, (2) duas vezes no ano anterior, (3) 3-5 vezes no ano anterior, (4) 6-10 vezes no ano anterior, (5) 1120 vezes no ano anterior, (6) mais de 20 vezes no ano anterior], sendo que as restantes se destinam à determinação a prevalência global: [(7) não no ano anterior, mas ocorreu anteriormente] e a inexistência deste tipo de abuso [(8) nunca aconteceu].
Como este instrumento avalia diferentes táticas de resolução de conflitos, designadamente as formas de abuso, é possível determinar a prevalência global, a prevalência do último ano, a frequência anual e a cronicidade. Para o presente estudo, avaliou-se a prevalência global através da recategorização a todas as categorias de resposta de 1 a 7 atribui-se o valor 1 (ocorreu em alguma altura) e à categoria 8 o valor 0 (nunca ocorreu).

\section{Procedimentos de Coleta de Dados e Éticos}

Numa fase inicial, realizaram-se os pedidos de autorização às autoras responsáveis pela validação do instrumento para o contexto português (CTS-2), para o uso do mesmo no âmbito do presente estudo. Após este pedido, procedeu-se à elaboração do respetivo protocolo de investigação, no qual consta a descrição dos objetivos do estudo, o método utilizado (participantes, instrumento utilizado - CTS-2), bem como o consentimento informado, o qual foi posteriormente submetido à validação da Comissão de Ética da universidade onde este estudou foi preparado.

Numa fase posterior, e após a obtenção das respetivas autorizações para o arranque do estudo, o CTS-2, o questionário de dados sóciodemográficos e respetivo consentimento informado dirigido aos/às participantes foram publicados em formato digital numa plataforma online - Google Docs - para que pudessem ser preenchidos online. Solicitou-se ainda a colaboração a várias associações LGBT (Lésbicas, Gays, Bissexuais, Transgéneros), com vista à divulgação e sensibilização do link do estudo junto da sua população-alvo - a comunidade LGBT - para eventual participação no estudo. Para além destas solicitações, solicitou-se a colaboração na divulgação junto de associações/núcleos de estudantes, através das suas mailing lists e difundiu-se o estudo através de contactos de e-mail das investigadoras (técnica snowball), fóruns e redes sociais. A recolha de dados realizou-se entre maio e setembro de 2014, estando o questionário disponível online apenas durante este período. Na parte inicial do questionário, os/as participantes foram confrontados/as com uma secção informativa relativa aos objetivos do estudo, critérios de inclusão na amostra e garantias de confidencialidade 
e anonimato dos dados fornecidos, num registo de cumprimento de todos os procedimentos éticos e deontológicos. No final do preenchimento dos instrumentos, foram disponibilizadas informações sobre a violência nos relacionamentos íntimos entre pessoas do mesmo sexo, designadamente da existência de entidades de apoio a vítimas e respetivos contactos das mesmas, para o caso de quererem obter informações adicionais ou necessitarem de algum tipo de apoio. Finda a recolha de dados, os mesmos foram transferidos para uma base de dados construída para o efeito com recurso ao programa informático Statistical Package for Social Sciences (IBM SPSS versão 22.0) para assim se dar início ao processamento estatístico dos dados e análise dos resultados.

Quanto às respostas obtidas, torna-se pertinente realçar que só foram considerados os questionários que cumpriram os critérios de inclusão, integrando assim a amostra final.

\section{Procedimentos de Análise de Dados}

Os dados recolhidos neste estudo foram sujeitos a análises estatísticas com recurso ao programa informático IBM SPSS versão 22.0. Numa primeira fase, foram realizadas análises descritivas para a caracterização da amostra e estimar a prevalência das diferentes formas de abuso íntimo medidos pelo CTS-2. Seguidamente, efetuaram-se análises inferenciais, com recurso a testes não paramétricos, entre alguns dados sociodemográficos dos/as participantes e o CTS-2, designadamente o teste de Mann-Whitney para analisar a relação entre os comportamentos abusivos e o sexo dos/as participantes, entre comportamentos abusivos e o tipo de relacionamento íntimo (relacionamento íntimo sem ou com coabitação) e o coeficiente de correlação de Spearman para analisar a relação entre a duração do relacionamento e a prevalência dos comportamentos abusivos. Procedeu-se ainda, e com recurso ao SPSS, ao cálculo dos tamanhos de efeito em linguagem comum para o teste Mann-Whitney, seguindo a fórmula TDE-LC $=\mathrm{U} / \mathrm{mn}$ em que $U$ é a estatística $U$ de Mann-Whitney, m é o número de participantes na primeira amostra e $\mathrm{n}$ o número de pessoas na segunda amostra (Espírito-Santo \& Daniel, 2015). O recurso a testes não paramétricos deveu-se ao fato de, após a avaliação da normalidade das distribuições, se ter verificado que estas não cumpriam os pressupostos que conferem rigor estatístico aos testes paramétricos.

\section{Resultados}

\section{Prevalência dos Comportamentos Abusivos Perpetrados e Sofridos}

No conjunto dos/as participantes que revelaram ter experiência em relacionamentos íntimos entre parceiros/as do mesmo sexo, $92,3 \%$ relatou a existência de pelo menos um comportamento violento no seu relacionamento íntimo, no decorrer do último ano. Mais concretamente, 91,7\% da amostra relatou ter sido vítima de pelo menos um ato abusivo durante o último ano e $92,3 \%$ admitiu a adoção deste tipo de conduta em relação ao/à seu/sua parceiro/a, no mesmo período.

Relativamente aos diferentes tipos de violência analisados pelo CTS-2, é possível verificar-se, em termos de vitimação, uma preponderância da agressão psicológica, tendo sido a vitimação por agressão psicológica ligeira relatada por $69,2 \%$ dos participantes e a severa por $30,4 \%$. A coerção sexual surge como sendo a menos reportada, tendo sido a coerção sexual ligeira referida por $29,2 \%$ da amostra enquanto que a coerção sexual severa foi admitida por 3,6\%. Ainda no que se refere à vitimação, constatou-se que os comportamentos fisicamente abusivos que não deixam sequelas se elevam ligeiramente face aos que deixam sequelas. Desta feita, o abuso físico sem sequelas ligeiro foi relatado por $28,6 \%$ da amostra, o abuso físico sem sequelas severo foi indicado por $11,9 \%$ enquanto que no abuso com sequelas, o abuso físico ligeiro foi reportado por $10,7 \%$ dos/as participantes e o severo por $1,2 \%$.

Quanto à perpetração, e tal como verificado na vitimação, observa-se uma elevação da agressão psicológica face ao abuso físico e à coerção sexual. Deste modo, $70,2 \%$ dos casos admitiram a prática da agressão psicológica ligeira e 29,8\% a agressão psicológica severa. Já no que concerne aos comportamentos fisicamente abusivos, e tal como acontecia na vitimação, verificou-se uma ligeira elevação dos atos que não deixam 
sequelas relativamente aos que deixam. Assim, a prática de abuso físico sem sequelas ligeiro foi reportado por $26,8 \%$ da amostra, o abuso físico sem sequelas severo por $9,5 \%$, enquanto que nos atos que deixaram sequelas, verificou-se um índice de prevalência de $11,3 \%$ para o abuso físico ligeiro e de $1,8 \%$ para o abuso físico severo. Por sua vez, $28 \%$ dos/as participantes admitiu a adoção de comportamentos que se enquadram na coerção sexual ligeira e 1,2\% na coerção sexual severa.

Por último, e atendendo aos índices elevados de vitimação e prevalência, foi possível verificar, através de uma análise de correlações de Spearman, a existência de correlações estatisticamente significativas entre os diferentes tipos de abuso perpetrados e vitimados, nomeadamente, no que diz respeito à perpetração e vitimação globais $(r h o=0,961 ; p=0,001)$.

\section{Comportamentos Abusivos e Sexo}

Ao comparar, com recurso ao teste de Mann-Whitney, os comportamentos abusivos relativamente ao sexo dos/as participantes, de uma perspetiva geral, constatou-se a não existência de diferenças de sexo estatisticamente significativas. No entanto, em termos de vitimação, apenas na coerção sexual ligeira, foi possível constatar a existência de diferenças significativas $[\mathrm{Z}(\mathrm{U})=-3,311 ; p=0,001]$, e em que os homens admitiram sofrer mais este tipo de comportamento (cf. Tabela1).

Em termos de perpetração, registou-se ao nível da coerção sexual ligeira diferença de sexo $[\mathrm{Z}(\mathrm{U})=-2,740 ; p=0,006]$. Assim, entre a perpetração da coerção sexual ligeira, encontraram-se mais participantes de sexo masculino do que de sexo feminino. Esta disparidade significativa de sexo foi igualmente detetada na perpetração do abuso físico com sequelas severo $[\mathrm{Z}(\mathrm{U})=-3,117$; $p=0,013]$ (cf. Tabela 1).

\section{Comportamentos Abusivos e Tipo de Relacionamento Íntimo}

No que respeita às diferenças entre o tipo de relacionamento íntimo dos/as participantes, encontraram-se, através do teste de Mann-Whitney, diferenças estatisticamente significativas em re- lação à vitimação do abuso físico sem sequelas severo $[Z(U)=-2,838 ; p=0,007]$, do abuso físico com sequelas ligeiro $[Z(U)=-2,156 ; p=0,033]$ e da agressão psicológica ligeira $[Z(U)=-3,735$; $p=0,001]$, indicando um maior índice de prevalência destas formas de abuso em relacionamentos com coabitação quando comparados aos relacionamentos sem coabitação. Esta tendência relativa à prevalência mais elevada em contextos relacionais de coabitação relativamente aos sem coabitação, também se constatou na perpetração de comportamentos abusivos, nomeadamente, no abuso físico sem sequelas ligeiro $[Z(U)=$ $2,063 ; p=0,032]$, no abuso físico sem sequelas severo $[Z(U)=-2,038 ; p=0,044]$ e na agressão psicológica ligeira $[Z(U)=-2,927 ; p=0,002]$ (cf. Tabela 4).

\section{Comportamentos Abusivos e Duração do Relacionamento}

Para analisar a relação entre a duração do relacionamento e a prevalência dos comportamentos abusivos no mesmo, utilizou-se o coeficiente de correlação de Spearman (cf. Tabela 3). Desta forma, os resultados demonstraram que apenas a vitimação da agressão psicológica ligeira (rho $=0,172 ; p=0,040)$ e a perpetração do abuso físico sem sequelas ligeiro ( $\mathrm{rho}=0,218$; $p=0,007$ ) se encontram significativa e positivamente relacionados com a duração do relacionamento, sugerindo que, quanto maior a duração da relação de intimidade, maior a probabilidade de ocorrer vitimação da agressão psicológica severa e/ou adotar comportamentos fisicamente abusivos e severos que deixam sequelas.

\section{Discussão dos Resultados}

$\mathrm{O}$ presente estudo procurou caracterizar a prevalência dos comportamentos abusivos em relacionamentos de intimidade entre pessoas do mesmo sexo e analisar a relação desta com características sociodemográficas dos participantes. Os dados apurados reforçam as conclusões de diversos estudos que se debruçam sobre esta temática, indicando que neste tipo de relações também se encontram comportamentos considerados abusivos (e.g., Antunes \& Machado, 
Tabela 3

Comparação, por Sexo, da Prevalência dos Comportamentos Abusivos

\begin{tabular}{|c|c|c|c|c|c|c|c|}
\hline & \multirow[t]{2}{*}{ Tipos de Abuso } & \multicolumn{2}{|c|}{ Mascuulino } & \multicolumn{2}{|c|}{ Feminino } & \multirow[b]{2}{*}{$Z(U)$} & \multirow[b]{2}{*}{ TDE-LC } \\
\hline & & $n$ & $\begin{array}{l}\text { Ordem } \\
\text { Média }\end{array}$ & $n$ & $\begin{array}{l}\text { Ordem } \\
\text { Média }\end{array}$ & & \\
\hline \multirow{9}{*}{ 胥 } & Global & 40 & 85,20 & 128 & 84,28 & $-0,218$ & 0,49 \\
\hline & Físico sem Sequelas Ligeiro & 39 & 85,69 & 128 & 83,48 & $-0,318$ & 0,49 \\
\hline & Físico sem Sequelas Severo & 40 & 82,90 & 128 & 85,00 & $-0,425$ & 0,49 \\
\hline & Físico com Sequelas Ligeiro & 40 & 83,35 & 127 & 84,20 & $-0,182$ & 0,49 \\
\hline & Físico com Sequelas Severo & 40 & 87,70 & 128 & 83,50 & $-2,537$ & 0,48 \\
\hline & Psicológico Ligeiro & 38 & 76,29 & 124 & 83,10 & $-1,009$ & 0,46 \\
\hline & Psicológico Severo & 39 & 86,33 & 128 & 83,29 & $-0,431$ & 0,48 \\
\hline & Coerção Sexual Ligeira & 40 & 102,00 & 128 & 79,03 & $-3,311 * *$ & 0,36 \\
\hline & Coerção Sexual Severa & 40 & 87,80 & 128 & 83,47 & $-1,529$ & 0,47 \\
\hline \multirow{9}{*}{ 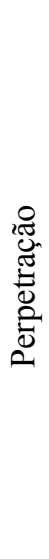 } & Global & 40 & 84,70 & 128 & 84,44 & $-0,064$ & 0,50 \\
\hline & Físico sem Sequelas Ligeiro & 40 & 85,10 & 128 & 84,31 & $-0,117$ & 0,50 \\
\hline & Físico sem Sequelas Severo & 40 & 87,00 & 128 & 83,72 & $-0,732$ & 0,48 \\
\hline & Físico com Sequelas Ligeiro & 39 & 83,06 & 128 & 84,25 & $-0,251$ & 0,49 \\
\hline & Físico com Sequelas Severo & 40 & 89,30 & 128 & 83,00 & $-3,117^{*}$ & 0,46 \\
\hline & Psicológico Ligeiro & 38 & 78,76 & 125 & 82,98 & $-0,623$ & 0,47 \\
\hline & Psicológico Severo & 40 & 84,70 & 128 & 84,44 & $-0,038$ & 0,50 \\
\hline & Coerção Sexual Ligeira & 40 & 98,80 & 128 & 80,03 & $-2,740 * *$ & 0,39 \\
\hline & Coerção Sexual Severa & 40 & 85,60 & 128 & 84,16 & $-0,872$ & 0,49 \\
\hline
\end{tabular}

** $p<0,01 ;{ }^{*} p<0,05 ;+$ parcialmente significativo.

2005; Burke, Jordan, \& Owen, 2002; Costa et al., 2011; Yu et al., 2013), levantando assim, questões acerca da prevalência da violência em relações entre parceiros do mesmo sexo.

No que diz respeito à prevalência da violência, de uma forma global, verificou-se que esta apresenta índices muito elevados, tanto em termos de perpetração como de vitimação. No presente estudo, as taxas de prevalência dos diferentes tipos de comportamentos abusivos apurados apresentam uma elevação significativa, quando comparadas com outros estudos, que apontam para taxas compreendidas entre os 7,6\% e 57,7\% (Finneran \& Stephenson, 2012; Frankland \& Brown, 2014; Milletich, Gumienny, Kelley, \& D'Lima, 2014; Pantalone, Schneider, Valentine, \& Simoni, 2012; Yu et al., 2013). Não obstante, os resultados do nosso estudo vão de encontro ao apurado por Turell e Cornell-Swanson (2005), o qual encontrou também uma taxa de prevalência elevada, de $89 \%$.

Cruzando os nossos dados com as evidências obtidas por outras investigações realizadas no contexto português, percebe-se igualmente que as taxas de abuso por nós encontradas são claramente superiores aos índices de abuso apurados no estudo de Antunes e Machado (2005), no qual $20,6 \%$ dos/as participantes referiu a vitimação de pelo menos um ato abusivo e 15,9\% admitiu a perpetração de algum comportamento violento, e, posteriormente, aos encontrados por Costa et al. (2011) que detetou um índice de perpetração de violência íntima de $39,1 \%$ e $37,7 \%$ de vitimação. 
Tabela 4

Comparação, por Tipo de Relacionamento Íntimo, da Prevalência dos Comportamentos Abusivos

\begin{tabular}{|c|c|c|c|c|c|c|c|}
\hline & \multirow[t]{2}{*}{ Tipos de abuso } & \multicolumn{2}{|c|}{$\begin{array}{c}\text { Com } \\
\text { Coabitação }\end{array}$} & \multicolumn{2}{|c|}{$\begin{array}{c}\text { Sem } \\
\text { Coabitação }\end{array}$} & \multirow[b]{2}{*}{$Z(U)$} & \multirow[b]{2}{*}{ TDE-LC } \\
\hline & & $n$ & $\begin{array}{l}\text { Ordem } \\
\text { média }\end{array}$ & $n$ & $\begin{array}{l}\text { Ordem } \\
\text { média }\end{array}$ & & \\
\hline \multirow{9}{*}{ 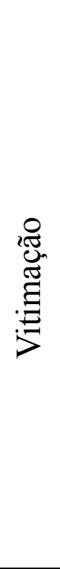 } & Global & 47 & 88,72 & 120 & 82,15 & $-1,702$ & 0,46 \\
\hline & Físico sem Sequelas Ligeiro & 47 & 91,29 & 119 & 80,42 & $-1,671$ & 0,43 \\
\hline & Físico sem Sequelas Severo & 47 & 93,54 & 120 & 80,26 & $-2,838 * *$ & 0,42 \\
\hline & Físico com Sequelas Ligeiro & 47 & 90,39 & 119 & 80,78 & $-2,156^{*}$ & 0,44 \\
\hline & Físico com Sequelas Severo & 47 & 83,00 & 120 & 84,39 & $-0,888$ & 0,49 \\
\hline & Psicológico Ligeiro & 46 & 97,75 & 115 & 74,30 & $-3,735 * * *$ & 0,35 \\
\hline & Psicológico Severo & 47 & 86,26 & 119 & 82,41 & $-0,581$ & 0,48 \\
\hline & Coerção Sexual Ligeira & 47 & 86,15 & 120 & 83,16 & $-0,456$ & 0,49 \\
\hline & Coerção Sexual Severa & 47 & 82,78 & 120 & 84,48 & $-0,635$ & 0,48 \\
\hline \multirow{9}{*}{ 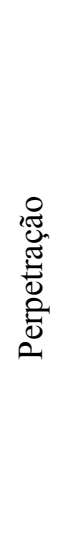 } & Global & 47 & 88,22 & 120 & 82,35 & $-1,579$ & 0,46 \\
\hline & Físico sem Sequelas Ligeiro & 47 & 93,48 & 120 & 80,29 & $-2,063^{*}$ & 0,42 \\
\hline & Físico sem Sequelas Severo & 47 & 90,21 & 120 & 81,57 & $-2,038^{*}$ & 0,45 \\
\hline & Físico com Sequelas Ligeiro & 47 & 88,13 & 119 & 81,67 & $-1,414$ & 0,46 \\
\hline & Físico com Sequelas Severo & 47 & 84,28 & 120 & 83,89 & $-0,201$ & 0,50 \\
\hline & Psicológico Ligeiro & 46 & 94,70 & 116 & 76,27 & $-2,927^{* *}$ & 0,39 \\
\hline & Psicológico Severo & 47 & 83,87 & 120 & 84,05 & $-0,027$ & 0,50 \\
\hline & Coerção Sexual Ligeira & 47 & 92,48 & 120 & 80,68 & $-1,821$ & 0,43 \\
\hline & Coerção Sexual Severa & 47 & 83,00 & 120 & 84,39 & $-0,888$ & 0,49 \\
\hline
\end{tabular}

$* * * p<0,001 ; * * p<0,01 ; * p<0,05$.

Concomitantemente, o apuramento, no presente estudo, de correlações positivas e significativamente estatísticas entre a perpetração e a vitimação global, remete-nos para a tese da bidirecionalidade da violência, comummente sustentada em estudos desta natureza (Costa et al., 2011; Oringher \& Samuelshon, 2011). Todavia, torna-se imperativo realçar que, apesar de estes valores, tanto da prevalência global como das diferentes formas de violência mais específicas, serem preocupantes, a avaliação feita incidiu sobre a presença de diferentes atos abusivos, pelo menos uma vez durante o último ano. Assim, e considerando as limitações deste estudo, os resultados obtidos devem ser interpretados de forma cautelosa.
Os comportamentos abusivos mais comumente referidos pelos/as participantes foram, sobretudo a agressão psicológica, tanto na forma ligeira como severa, quer ao nível da vitimação $(69,6 \%$ vs 30,4\%) e perpetração $(70,2 \%$ vs $29,8 \%$ ). Estes dados corroboram o que tem sido verificado em outros estudos nacionais e internacionais (Antunes \& Machado, 2005; Costa et al., 2011; Finneran \& Stephenson, 2013; Matte \& Lafontaine, 2011; Pantalone et al., 2012; Turell, 2000; Yu et al., 2013). Não obstante, outros estudos (Blosnich \& Bossarte, 2009; Edwards \& Sylaska, 2013; Halpern et al., 2004; Ramachandran, Yonas, Silvestre, \& Burke, 2010) demonstram que a violência física é a mais frequente. Contudo, e relativamente ao índice de prevalên- 
Tabela 5

Relação entre a Duração do Relacionamento Íntimo e a Prevalência dos Comportamentos Abusivos

\begin{tabular}{|c|c|c|}
\hline & & Coeficiente de Correlação Spearman's rho \\
\hline \multirow{9}{*}{ 胥 } & Global & $-0,016$ \\
\hline & Físico sem Sequelas Ligeiro & 0,118 \\
\hline & Físico sem Sequelas Severo & 0,104 \\
\hline & Físico com Sequelas Ligeiro & 0,076 \\
\hline & Físico com Sequelas Severo & $-0,109$ \\
\hline & Psicológico Ligeiro & $0,172 *$ \\
\hline & Psicológico Severo & 0,006 \\
\hline & Coerção Sexual Ligeira & 0,024 \\
\hline & Coerção Sexual Severa & $-0,040$ \\
\hline \multirow{9}{*}{ 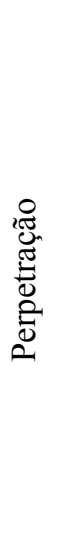 } & Global & 0,013 \\
\hline & Físico sem Sequelas Ligeiro & $0,218 * *$ \\
\hline & Físico sem Sequelas Severo & 0,046 \\
\hline & Físico com Sequelas Ligeiro & 0,135 \\
\hline & Físico com Sequelas Severo & $-0,058$ \\
\hline & Psicológico Ligeiro & 0,136 \\
\hline & Psicológico Severo & $-0,054$ \\
\hline & Coerção Sexual Ligeira & 0,051 \\
\hline & Coerção Sexual Severa & $-0,008$ \\
\hline
\end{tabular}

${ }^{*} p<0,05 ; * * p<0,01$

cia desta forma de violência, esta assumiu valores mais elevados do que na maioria dos estudos desenvolvidos, revelando-se congruente com dois estudos levados a cabo com o mesmo instrumento (Craft \& Serovich, 2005; Matte \& Lafontaine, 2011) e três com um questionário de autorrelato não especificado (Blosnich \& Bossarte, 2009; Donovan, Hester, Holmes, \& McCarry, 2006; Turell, 2000). Estes resultados destacam-se essencialmente pelos elevados e alarmantes índices de agressão psicológica nos relacionamentos íntimos, não sendo apenas a manifestação mais frequente de violência nos mesmos. Assim, por um lado, surge a questão relativamente ao(s) próprio(s) instrumento(s) utilizado(s), se está mais sensível ao reconhecimento desta forma abusiva, maximizando a sua ocorrência ou se a violência psicológica tem sido adotada como sendo uma tática de resolução de conflitos nos relacionamentos amorosos de uma forma natural (Bolze, Schmidt, Crepaldi, \& Vieira, 2013; Mosmann \& Falcke, 2011). Por outro lado, e considerando que os episódios abusivos tendem a iniciar-se com comportamentos "menos violentos" assumindo, à posteriori, atos ditos "mais violentos", a agressão psicológica constitui um preditor de outras formas de violência (Antunes \& Machado, 2005), não devendo por isso, esta preponderância, promover uma visão microscópica e fragmentada do fenômeno nem à sua desvalorização nestes contextos relacionais.

No presente estudo, a coerção sexual na forma ligeira, tanto perpetrada como vitimada, assume-se como o tipo de abuso mais prevalente a seguir à agressão psicológica (28\% vs 29,2\%). Esta evidência foi também verificada noutros es- 
tudos, nos quais os valores se situam entre $9,6 \%$ e 40,5\% (Donovan et al., 2006; Toro-Alfonso, 1999; Toro-Alfonso \& Rodríguez-Madera, 2004b; Yu et al., 2013). Outras investigações (Blosnich \& Bossarte, 2009; Craft \& Serovich, 2005; Ramachandran et al., 2010) revelaram valores relativamente similares, estando estes compreendidos entre $27,5 \%$ e $33 \%$. Esta tendência revelada pelos participantes para mais facilmente relatarem a agressão psicológica e a coerção sexual deve, contudo, ser cuidadosamente analisada na medida em que isto poderá estar associado a um certo enviesamento cultural. Percebidos como comportamentos que tendem a ser socialmente mais aceites, a sua admissão parece assumir um caráter de culpabilização menor quando comparados à violência física que tende a ser mais estigmatizada do ponto de vista social (Paiva \& Figueiredo, 2005).

No que diz respeito à prevalência do abuso físico apurada neste estudo, constata-se que aquele que não deixa sequelas assume uma taxa mais elevada que o com sequelas. Desta feita, $26,8 \%$ dos/as participantes admitiu a perpetração do abuso físico sem sequelas ligeiro, 9,5\% na forma severa, enquanto que $11,3 \%$ referiu a adoção de abuso físico com sequelas ligeiro e $1.8 \%$ na forma severa. Por seu turno, e no que se refere à vitimação, $28,6 \%$ da amostra referiu a existência de abuso físico sem sequelas ligeiro, $11,9 \%$ de abuso físico sem sequelas severo, $10,7 \%$ de abuso físico com sequelas ligeiro e $1,2 \%$ de abuso físico com sequelas severo. Embora os estudos desenvolvidos neste âmbito não procurem, geralmente, distinguir abuso físico com sequelas do abuso físico sem sequelas, é possível constatar semelhanças nas taxas de prevalência dos mesmos, as quais se encontram compreendidas entre os $7,9 \%$ e os $31 \%$ (Antunes \& Machado, 2005; Costa et al., 2011; Edwards \& Sylaska, 2013; Finneran \& Stephenson, 2013; Halper et al., 2004; Houston \& McKirnan, 2007; Matte \& Lafontaine, 2011; Pantalone et al., 2012; Ramachandran et al., 2010; Turell, 2000; Yu et al., 2013) e dissemelhanças ao nível da sua inferioridade face a outros estudos que apuraram índices entre os $45,1 \%$ e $89,9 \%$ (Blosnich \& Bossarte, 2009; Craft \& Serovich,
2005; Greenwood et al., 2002). Mais uma vez, a estigmatização social desta forma de violência poderá contribuir para a compreensão do menor volume de relatos deste tipo de abuso por parte dos/as participantes (Paiva \& Figueiredo, 2005). Não obstante, torna-se imperativo referir que a grande dispersão registada nos índices de prevalência pelos diferentes estudos desenvolvidos acerca do abuso íntimo entre parceiros/as do mesmo sexo tem sido comummente associada a problemas metodológicos (Donovan et al., 2006; Murray, Mobley, Buford, \& Seaman-DeJohn, 2006/2007). Designadamente, devido às características das amostras (Buller, Devries, Howard, \& Bacchus, 2014; Burke \& Follingstad, 1999; Rohrbaugh, 2006; Tjaden \& Thoennes, 2000), à natureza da medida, ao tipo de instrumentos, à definição de abuso íntimo (Buller et al., 2014), entre outros. Assim, os valores encontrados neste estudo poderão decorrer de especificidades inerentes à própria amostra.

No que concerne às diferenças de sexo, apenas se encontraram diferenças estatisticamente significativas na perpetração da coerção sexual, tanto ligeira como severa, sugerindo que os elementos de sexo masculino assumem adotar mais este tipo de comportamento quando comparados com os elementos de sexo feminino, ainda que ambos admitam a perpetração e vitimação destes comportamentos. Embora não se verifiquem conclusões similares, nomeadamente no que diz respeito à coerção sexual, na investigação sobre a violência em relacionamentos íntimos entre parceiros do mesmo sexo, é possível verificar que o homem tende a ser associado ao uso da agressividade física na resolução dos seus conflitos interpessoais (Antunes \& Machado, 2005).

Relativamente às diferenças face ao tipo de relacionamento, apenas se encontraram diferenças com relevância estatística, ao nível da vitimação, no abuso físico sem sequelas severo, no abuso físico com sequelas ligeiro e na agressão psicológica, no abuso físico sem sequelas ligeiro, no abuso físico sem sequelas severo e na agressão psicológica, ao nível da perpetração, demonstrando uma maior prevalência em contextos relacionais de coabitação. A literatura revela que a ocorrência dos atos abusivos tende 
a ser mais provável em relações nas quais existe coabitação (Bolze et al., 2013; Mosmann \& Falcke, 2011) e o qual poderá estar relacionado com o maior comprometimento e envolvimento relacional.

Quanto à duração do relacionamento, foi possível observar que esta se encontra positiva e significativamente correlacionada apenas com a vitimação da agressão psicológica ligeira e a perpetração do abuso físico sem sequelas ligeiro. Neste sentido, quanto maior a duração do relacionamento, maior a probabilidade de ocorrerem estas formas de violência. Efetivamente, a investigação sobre os relacionamentos íntimos tem demonstrado a existência de uma escalada da violência com o decorrer da relação (Antunes \& Machado, 2005; Mahoney, Williams, \& West, 2001), sendo por isso imperativo não menosprezar qualquer ato abusivo nos relacionamentos.

\section{Conclusão}

Este estudo, ao focar-se na violência em relacionamentos íntimos entre parceiros do mesmo sexo, contribuiu para o conhecimento de uma realidade que tem sido amplamente ignorada pela comunidade científica, mais focalizada em relacionamentos íntimos heterossexuais, sendo imperativa a não restrição do estudo do tema às relações ditas tradicionais (Antunes \& Machado, 2005). Mais concretamente, e no que ao contexto português diz respeito, este estudo revela aquilo que parcos estudos nacionais têm mostrado (cf. Antunes \& Machado, 2005; Costa et al., 2011), a existência de fenômenos de violência em relacionamentos íntimos entre pessoas do mesmo sexo, permitindo observar resultados mais expressivos do que já havia sido demonstrado, tal como, a presença de indícios da bidirecionalidade da violência. Assim, os elevados índices de prevalência apurados neste estudo reiteram a urgência em conferir maior visibilidade a este fenómeno que se caracteriza, socialmente, pela sua "dupla invisibilidade" (Antunes \& Machado, 2005, p. 167). Tal poderá dever-se ao facto de os casais de indivíduos do mesmo sexo serem confrontados com o medo adicional de discriminação que se manifesta, em grande parte, pela homofobia e condenação da homossexualidade, o que consequentemente fomenta o segredo a que as situações de violência são “impostas". Por outro lado, esta necessidade imperativa no aprofundamento de conhecimento, permitir-nos-á, invariavelmente, dar resposta aos indivíduos envolvidos em relacionamentos abusivos, não só através do desenvolvimento de mecanismos (in)formais de apoio aos diferentes tipos de vítimas (e.g., criação de abrigos destinados a mulheres vítimas de violência por um parceiro íntimo do mesmo sexo, evitando que haja um encontro ofensor-vítima, e também para os próprios homens), como também na ação da sua prevenção, através da elaboração e implementação de esforços preventivos mais ajustados à realidade em questão.

Não obstante, o estudo, caracterizado pelo seu caráter quantitativo, não permite compreender algumas questões relacionadas com as motivações subjacentes à experiência abusiva e à adoção destes comportamentos abusivos (e.g., autodefesa), o contexto de instalação, a sequência interativa da experiência abusiva nem a significação atribuída ao abuso pelos seus intervenientes. Por outro lado, este estudo não atende à frequência dos atos abusivos, bastando que os mesmos ocorram uma vez para serem contabilizados, não se verificando por isso, a evolução dos mesmos (e.g., escalada da violência). É de referir que, devido à dificuldade de acesso à população que mantém relacionamentos íntimos homossexuais, a amostra deste estudo é pequena, maioritariamente composta por elementos do sexo feminino e, como a maioria dos estudos nesta área, é uma amostra por conveniência, não sendo, por isso, representativa, o que não permite extrair deste, generalizações para a população portuguesa. $\mathrm{O}$ instrumento utilizado tem escalas validadas para amostras heterossexuais, o que consequentemente pode levar ao condicionamento dos relatos factuais da amostra e à não mensuração real do fenómeno nas relações entre pessoas do mesmo sexo (Buller et al., 2014). Neste sentido, assume-se como urgente o aprofundamento da investigação, não apenas de índole quantitativa, mas também qualitativa, sobre a violência nos relacionamentos íntimos en- 
tre indivíduos do mesmo sexo que contemplem, preferencialmente, amostras mais alargadas e representativas desta população, nomeadamente em Portugal. Assim, é imperativa a determinação de índices de prevalência nesta população, no sentido de diminuir as discrepâncias anteriormente referidas e a compreensão de significados, motivações, contextos e sequências interativas inerentes a este fenómeno, tanto numa perspetiva de perpetração como de vitimação.

\section{Referências}

Antunes, R., \& Machado, C. (2005). Dupla invisibilidade: A violência nas relações homossexuais. Psychologica, 39, 167-187.

Banks, J. R., \& Fedewa, A. L. (2012). Counselors' attitudes toward domestic violence in same-sex versus opposite-sex relationships. Journal of Multicultural Counseling and Development, 40, 194-205. doi:10.1002/j.21611912.2012.00017.x

Bolze, S. D. A., Schmidt, B., Crepaldi, M. A., \& Vieira, M. L. (2013). Relacionamento conjugal e táticas de resolução de conflito entre casais. Actualidades en Psicología, 27(114), 71-85.

Blosnich, J. R., \& Bossarte, R. M. (2009). Comparisons of intimate partner violence among partners in same-sex and opposite-sex relationships in the United States. American Journal of Public Health, 99(12), 2182-2184. doi:10.2105/ AJPH.2008.139535

Buller, A. M., Devries, K. M., Howard, L. M., \& Bacchus, L. J. (2014) Associations between intimate partner violence and health among men who have sex with men: A systematic review and meta-analysis. PLoS Med 11(3), e1001609. doi:https://doi.org/10.1371/journal. pmed.1001609

Burke, L. K., \& Follingstad, D. R. (1999). Violence in lesbian and gay relationships: Theory, prevalence, and correlational factors. Clinical Psychology Review, 19(5), 487-512.

Burke, T. W., Jordan, M. L., \& Owen, S. S. (2002). A cross-national comparison of gay and lesbian domestic violence. Journal of Contemporary Criminal Justice, 18(3), 231-257.

Carvalho, A. F., Lewis, R. J., Derlega, V. J., Winstead, B. A., \& Viggiano, C. (2011). Internalized sexual minority stressors and same-sex intimate partner violence. Journal of Family Violence, 26, 501-509.

Cezario, A. C. F., Fonseca, D. S., Lopes, N. C., \& Lourenço, L. M. (2015). Violência entre parceiros íntimos: Uma comparação dos índices em relacionamentos hetero e homossexuais. Temas em Psicologia, 23(3), 565-575. doi:10.9788/ TP2015.3-04

Costa, L. G., Machado, C., \& Antunes, R. (2011). Violência nas relações homossexuais: A face oculta da agressão na intimidade. Psychologica, 1, 2-15.

Craft, S. M., \& Serovich, J. M. (2005). Family-of-origin factors and partner violence in the intimate relationships of gay men who are HIV positive. Journal of Interpersonal Violence, 20(7), 777 791. doi:10.1177/0886260505277101

Donovan, C., Hester, M., Holmes, J., \& McCarry, M. (2006). Comparing domestic abuse in same sex and heterosexual relationships. Recuperado em http://www.bris.ac.uk/sps/research/projects/ completed/2006/rc1307/rc1307finalreport.pdf

Edwards, K. M., \& Sylaska, K. M. (2013). The perpetration of intimate partner violence among LGBTQ college youth: The role of minority stress. Journal of Youth and Adolescence, 42, 17211731. doi:10.1007/s10964-012-9880-6

Espírito-Santo, H., \& Daniel, F. (2015). Calcular e apresentar tamanhos do efeito em trabalhos científicos (1): As limitações do $p<0,05$ na análise de diferenças de médias de dois grupos. Revista Portuguesa de Investigação Comportamental e Social, 1(1), 3-16.

Finneran, C., \& Stephenson, R. (2012). Intimate partner violence among men who have sex with men: A systematic review. Trauma, Violence, \& Abuse, 14(2), 168185. doi: $10.1177 / 1524838012470034$

Finneran, C., \& Stephenson, R. (2013). Gay and bisexual men's perceptions of police helpfulness in response to male-male intimate partner violence. Western Journal of Emergency Medicine, 14(4), 354-362. doi:10.5811/westjem.2013.3.15639

Frankland, A., \& Brown, J. (2014). Coercive control in same-sex intimate partner violence. Journal of Family Violence, 29, 15-22.

Freedner, N., Freed, L. H., Yang, Y. W., \& Austin, S. B. (2002). Dating violence among gay, lesbian, and bisexual adolescents: Results from a community survey. Journal of Adolescent Health, 
31, 469-474. doi:http://dx.doi.org/10.1016/ S1054-139X(02)00407-X

Greenwood, G. L., Relf, M. V., Huang, B., Pollack, L. M., Canchola, J. A., \& Catania, J. A. (2002). Battering victimization among a probabilitybased sample of men who have sex with men. American Journal of Public Health, 92(12), 1964-1969. Recuperado em http://www.ncbi. nlm.nih.gov/pmc/articles/PMC1447360/.

Halpern, C. T., Young, M. L., Waller, M. W., Martin, S. L., \& Kupper, L. L. (2004). Prevalence of partner violence in same-sex romantic and sexual relationships in a national sample of adolescents. Journal of Adolescent Health, 35, 124 131.

Houston, E., \& McKirnan, D. J. (2007). Intimate partner abuse among gay and bisexual men: Risk correlates and health outcomes. Journal of Urban Health: Bulletin of the New York Academy of Medicine, 84(5), 682-690.

Jasinski, J. L., \& Williams, L. M. (Eds.). (1998). Partner violence: A comprehensive review of twenty years of research. Thousand Oaks, CA: Sage.

Little, B., \& Terrance, C. (2010). Perceptions of domestic violence in lesbian relationships: Stereotypes and gender role expectations. Journal of Homosexuality, 57, 429-440. doi:10.1080/00918360903543170

Mahoney, P., Williams, L. M. \& West, C. M. (2001). Violence against women by intimate relationships partners. In C. M. Renzetti, J. L. Edleson, \& R. K. Bergen (Eds.), Sourcebook on violence against women (143-178). Thousand Oaks, CA: Sage.

Matte, M., \& Lafontaine, M.F. (2011). Validation of a measure of psychological aggression in samesex couples: Descriptive data on perpetration and victimization and their association with physical violence. Journal of GLBT Family Studies, 7(3), 226-244. doi:10.1080/1550428X.2011.564944

Milletich, R. J., Gumienny, L. A., Kelley, M. L., \& D'Lima, G. M. (2014). Predictive factors for intimate partner violence against women. Journal of Family Violence, 29(6), 653-664. doi:10.1007/ s10896-014-9620-7

Mosmann, C., \& Falcke, D. (2011). Conflitos conjugais: Motivos e frequência. Revista SPAGESP, 12(2), 5-16. Recuperado em http://pepsic.bvsalud.org/pdf/rspagesp/v12n2/v12n2a02.pdf
Murray, C. E., Mobley, A. K., Buford, A. P., \& Seaman-DeJohn, M. M. (2006/2007). Samesex intimate partner violence: Dynamics, social context, and counseling implications. The Journal of LGBT Issues in Counseling, 1(4), 7-30. Recuperado em https://libres.uncg.edu/ir/ uncg/f/AK_Mobley_Same_2007.pdf

National Coalition of Anti-Violence Programs Project. (2013). Lesbian, gay, bisexual, transgender, queer, and HIV-Affected intimate partner violence in 2012. A Report of the National Coalition of Anti-Violence Programs. New York: Author. Recuperado em http:// www.avp.org/storage/documents/ncavp_2012_ ipvreport.final.pdf \nhttp://www.avp.org/ storage/documents/ncavp_2012_hvreport_final. pdf

Oringher, J., \& Samuelshon, K. W. (2011). Intimate partner violence and the role of masculinity in male same-sex relationships. Traumatology, 17(2), 68-74. doi:10.1177/1534765610395620

Paiva, C., \& Figueiredo, B. (2005). Abuso no relacionamento íntimo e estado desaúde em jovens adultos portugueses.

Paiva, C., \& Figueiredo, B. (2006). Versão portuguesa das "Escalas de Táticas de Conflito Revisadas": Estudo de validação. Psicologia: Teoria e Prática, 8(2), 14-39. Recuperado em http://app. parlamento.pt/violenciadomestica/conteudo/ pdfs/biblioteca/paivacts2.pdf

Pantalone, D. W., Schneider, K. L., Valentine, S. E., \& Simoni, J. M. (2012). Investigating partner abuse among HIV-Positive men who have sex with men. AIDS and Behavior, 16, 1031-1043. doi:10.1007/s10461-011-0011-2

Ramachandran, S., Yonas, M. A, Silvestre, A. J., \& Burke, J. G. (2010). Intimate partner violence among HIV-positive persons in an urban clinic. AIDS Care, 22(12), 1536-1543. doi:10.1080/09 540121.2010.482199

Richards, A., Noret, N., \& Rivers, I. (2003). Violence and abuse in same-sex relationships: A review of literature. Leeds: University of Leeds, York St. John College. Recuperado em http://mesmac. co.uk/uploads/cms/files/violence_and_abuse. pdf.

Rohrbaugh, J. B. (2006). Domestic violence in same-gender relationships. Family Court Review, 44(2), 287-299. doi:10.1111/j.17441617.2006.00086.x 
Santos, A. C. (2012). Entre duas mulheres isso não acontece - Um estudo exploratório sobre violência conjugal lésbica. Revista Crítica de Ciências Sociais, 98, 3-24. Recuperado em https://rccs. revues.org/4988?lang=fr

Tjaden, P., \& Thoennes, N. (2000). Extent, nature, and consequences of intimate partner violence. Recuperado em https://www.ncjrs.gov/pdffiles1/nij/181867.pdf.

Toro-Alfonso, J. (1999). Domestic violence among same sex partners in Puerto Rico. Journal of Gay \& Lesbian Social Services, 9(1), 69-78. doi:10.1300/J041v09n01_04

Toro-Alfonso, J., \& Rodríguez-Madera, S. (2004). Sexual coercion in a sample of Puerto Rican gay males. Journal of Gay \& Lesbian Social Services, 17(1), 47-58. doi:10.1300/J041v17n01_04
Turell, S. C. (2000). A descriptive analysis of samesex relationship violence for a diverse sample. Journal of Family Violence, 15(3), 281-293.

Turell, S. C., \& Cornell-Swanson, L. V. (2005). Not all alike. Journal of Gay \& Lesbian Social Services, 18(1), 71-88. doi:10.1300/J041v18n01_06

Yu, Y., Xiao, S., \& Liu, K. Q. (2013). Dating violence among gay men in China. Journal of Interpersonal Violence, 28(12), 2491-2504. doi: $10.1177 / 0886260513479028$

Recebido: 21/03/2016

$1^{a}$ revisão: $1 \% 07 / 2016$

$2^{a}$ revisão: $10 / 07 / 2016$

Aceite final: 14/07/2016 